Article

\title{
Emergence of the Online-Merge-Offline (OMO) Learning Wave in the Post-COVID-19 Era: A Pilot Study
}

\author{
Ronghuai Huang ${ }^{1}$, Ahmed Tlili ${ }^{1} * \mathbb{E}$, Huanhuan Wang ${ }^{1}\left(\mathbb{D}\right.$, Yihong Shi ${ }^{1} \mathbb{D}$, Curtis J. Bonk ${ }^{2}$, Junfeng Yang ${ }^{3}$ and \\ Daniel Burgos $4,5, *$ (i)
}

1 Smart Learning Institute of Beijing Normal University, Beijing 100875, China; huangrh@bnu.edu.cn (R.H.); holly.08@live.cn (H.W.); shiyh@upenn.edu (Y.S.)

2 Instructional Systems Technology Department, School of Education, Indiana University, Bloomington, IN 47405, USA; cjbonk@indiana.edu

3 School of Education, Hangzhou Normal University, Hangzhou 311121, China; yjf@hznu.edu.cn

4 Research Institute for Innovation \& Technology in Education (UNIR iTED), Universidad Internacional de La Rioja (UNIR), 26006 Logroño, Spain

5 Research Unit Self-Directed Learning, Faculty of Education, North-West University, Potchefstroom 2531, South Africa

* Correspondence: ahmedtlili@ieee.org (A.T.); daniel.burgos@unir.net (D.B.)

Citation: Huang, R.; Tlili, A.; Wang, H.; Shi, Y.; Bonk, C.J.; Yang, J.; Burgos, D. Emergence of the

Online-Merge-Offline (OMO) Learning Wave in the Post-COVID-19 Era: A Pilot Study. Sustainability 2021, 13, 3512. https://doi.org/10.3390/ su13063512

Academic Editor: Jin Su Jeong

Received: 7 February 2021

Accepted: 15 March 2021

Published: 22 March 2021

Publisher's Note: MDPI stays neutral with regard to jurisdictional claims in published maps and institutional affiliations.

Copyright: (c) 2021 by the authors. Licensee MDPI, Basel, Switzerland. This article is an open access article distributed under the terms and conditions of the Creative Commons Attribution (CC BY) license (https:// creativecommons.org/licenses/by/ $4.0 /)$.

\begin{abstract}
The COVID-19 pandemic revealed the need for new innovative methods to effectively maintain education in times of crisis and uncertainty. This study first presents the Online-MergeOffline (OMO) learning approach, a way of learning that caters to the new needs of students and teachers in the post-COVID-19 era. OMO learning utilizes a hybrid infrastructure that combines Open Educational Practices and real-time learning spaces, both online and offline. This study then discusses the early results of a pilot experiment investigating OMO learning in China for three months from three dimensions: space design requirements, technological considerations, and pedagogical considerations. A qualitative, two-stage study focused on content analysis and a multiple-case study were carried out in the context of courses about English language learning with 30 teachers and students. The obtained findings showed that, although both teachers and students had a positive attitude towards OMO learning, they mentioned that a comprehensive set of core and functional competencies are needed-including the use of online platforms, communication skills, class management, and the effective use of resources. Additionally, the findings showed that more effort should be paid to classroom design, such as infrastructure, to efficiently support OMO learning. This study exemplifies a new approach toward the future of education to ensure sustainable education in this complex and uncertain world.
\end{abstract}

Keywords: online-merge-offline learning; COVID-19; learning space; open education; pandemic

\section{Introduction \\ 1.1. Education during the Post-COVID-19 Pandemic}

The COVID-19 pandemic has posed great challenges to the field of education. As of October 2020, more than 1.6 billion children and youth in 188 countries, accounting for $94 \%$ of the world's student population, have been affected by the pandemic [1-3]. To educate these youths, schools around the world have relied on traditional forms of distance education such as radio, TV, printed packets, and other more traditional studyat-home methods [4,5]. In a time of health crisis, countries have implemented policies such as travel restrictions, closing borders, and closing schools in order to contain the spread of the virus [6]. The unexpected health crisis pushed educators to design and implement innovative learning methods in response to this pandemic. The major change has been the transition to remote learning, giving rise to a significant increase in the use of distance learning technologies and techniques. Hodges et al. [7] define remote teaching 
as "a temporary shift of instructional delivery to an alternate delivery mode due to crisis circumstances. It involves the use of fully remote teaching solutions for instruction or education that would otherwise be delivered face-to-face or as blended or hybrid courses and that will return to that format once the crisis or emergency has abated".

Since the transition to remote teaching was fast and unexpected, several studies reported different challenges in this experience. For instance, van der Spoel et al. [8] investigated teachers' online teaching expectations and experiences during the COVID-19 pandemic in the Netherlands. Their results revealed that several teachers experienced some difficulties when using distance learning technologies, as they were not familiar with them. Similarly, la Velle et al. [9] revealed that teachers in England exhibited some negative feelings, including anxiety and panic, as they were not prepared for online education. To cope with this rapid change, several studies pointed out the importance of digital teaching competencies, which can encourage teaching innovation and result in better learning outcomes [10-12].

The world is slowly recovering from the global pandemic and the severe associated economic losses and monumental educational challenges. Europe is gradually bringing students back to campus while still maintaining online classes [13]. One key challenge during these times is that internationally enrolled students are stuck either in their destination country or home country, using online platforms to continue studying due to ongoing travel restrictions [14,15]. Most universities in the U.S. announced that online classes would continue to be offered after 2020 but limited in-person options would also be provided. Other countries such as China, by contrast, have already opened schools and universities again [16]. Kenya [17] planned to fully reopen schools in January 2021 and India started resuming in-person classes for senior students [18]. In terms of these in-person classes, schools and universities are putting many precautionary measures in place. For instance, classroom seats are spaced out, the enrolment capacity of classes is reduced, and there is limited interaction between groups [19].

\subsection{Research Motivation and Objectives}

The changes in education posed by COVID-19 have raised several challenges for the post-pandemic era. Teachers now have to teach the same course twice-offline for in-person class and online for the students who cannot come to the physical classroom. This can be extremely time-consuming and exhausting. Several universities worldwide are now providing the same learning content through online and in-person classes in order to take care of both the stay-at-campus students and the back-at-home student cohort [20-22]. Additionally, dividing students into offline and online classes to learn separately might reduce class interactivity and efficiency, which negatively affects learning outcomes [23]. Furthermore, due to safety policies adopted by schools and universities, such as respecting social distancing, conducting collaborative learning activities may not be a flexible option anymore. Given the status quo of COVID-19 and the rising tide of confirmed COVID-19 cases in some areas, the question of distance learning continues to be heatedly debated for countries that are experiencing the pandemic and post-pandemic eras. However, such policies and procedures are required to maintain educational continuity amid these uncertainties, and they point to the need to create a more dynamic and flexible mode of learning [24]. Petraglia [25] points out that additional research should be conducted to make online learning as authentic [26] for students as in-person learning.

Several studies highlight that, despite the actual use of technologies in education, more research is needed to investigate how these technologies can support teaching for pedagogical purposes [27,28]. The United Nations Educational, Scientific and Cultural Organization (UNESCO) has recently launched an initiative calling for more research and debate on how knowledge and education should be designed in a complex and uncertain world [2]. In line with this initiative, and inspired by the current COVID-19 pandemic, this paper presents a pilot study that investigated a unique Online-Merge-Offline (OMO) learning mode in China's post-pandemic era. This mode of learning uses ClassIn $\mathrm{X}$, a 
newly developed smart tool that extends the learning space by merging the physical classroom space with the online space using Open Educational Practices (OEP). This approach provides more flexibility for teachers to teach both online and offline students at the same time.

This approach can also create a more dynamic and authentic learning process, as both online and offline students can interact and work together, along with the teacher. Wiley and Hilton [29] define OEP as Open Educational Resource (OER) enabled pedagogies, a "set of teaching and learning practices that are only possible or practical in the context of the five R's (Retain, Reuse, Revise, Remix, and Redistribute) permissions that are characteristic of OER". In response, this study applied a qualitative analysis to assess the experiences of teachers and students of this new OMO learning method. We hope that the findings can help draw conclusions for further improvements and wider adoption of the method. The results of this study exemplify new approaches toward the future of education in providing open and flexible learning experiences in this complex and uncertain world by making use of the potential of different interactive technologies, tools, and systems, and associated pedagogies [30-32].

Filho et al. [33] stated that COVID-19 had a negative impact on sustainable teaching development worldwide. In particular, there has been a debate since the 1970s regarding changes in sustainable education, especially in a time of crisis [34]. According to McCowan [35], universities had a crucial role in the post-2015 development agenda and the achievement of sustainable development goals (SDG). In this context, Karatzoglou [36] argues that "universities continue to cope effectively and sustainably with the dynamic nature of sustainability by displacing barriers, changing teaching paradigms, developing social competencies, communication skills, and community relations". This role is more urgent than ever in the post-COVID-19 era, as teaching and learning processes must cater to the new needs of students. On the other hand, Filho et al. [33] state that new trends in society and technology with the fourth industrial revolution have provided new opportunities for sustainable education, especially in times of crisis. Similarly, Wolff [34] suggests that careful selection of methods, equipment, and technology is necessary for ensuring sustainable education, and that the perceptions towards them are very important [34]. As the old saying goes, a crisis is an opportunity for change. Therefore, the findings of this study not only exemplify a trend for future education but also provide support for sustainable education in times of uncertainty (e.g., crisis, sickness, pregnancy, etc.) by providing innovative ways of maintaining education from home.

\section{Study Context: OMO Learning}

The concept of Online to Offline (O2O) was first proposed in 2010 to increase opportunities in e-commerce by merging together offline and e-services [37]. The $\mathrm{O} 2 \mathrm{O}$ business model inspired educators to rethink how to combine the strength of both offline and online environments to further benefit students and instructors, especially in the post-COVID-19 era. Specifically, the post-pandemic era has highlighted the need for new learning methods, as some students will be learning online while their peers can learn offline, in the physical classroom. This has created a challenge for teachers regarding how to teach online and offline students at the same time while ensuring the same level of learning efficiency.

To cope with this educational challenge during the post-pandemic era, technologies have been adopted to facilitate a new mode of learning-namely, Online-Merge-Offline $(\mathrm{OMO})$. This study conceptualizes OMO learning as a learning mode that relies on hybrid infrastructure and open educational practices to merge online and offline (i.e., physical classrooms) learning spaces together in real-time while simultaneously seamlessly teaching students in both the physical classroom and online. In doing so, the learning experience is shared by the group through the combination of two different yet connected settings. In addition, in OMO learning, the teacher has to design learning activities that foster interaction between online and offline students for better learning outcomes. This means that, in the ideal context of OMO learning, technology and open educational resources 
not only assist the learning and teaching processes but also foster communication and interaction among teachers and students (i.e., online and offline), even though they are situated in different learning spaces. The goal is to provide authentic and innovative learning experiences. Hilliard et al. [38] state that traditional methods of online instruction are now changing, with the design of more collaborative learning environments and instructions that foster discussions and collaboration between students [39].

Petraglia [25] highlights the importance of merging together online and offline learning environments in order to make online learning more authentic. This means that, when the design of an online learning environment is ultimately separated from students' real-life environments, it is inevitably challenging to make online learning an authentic experience. Xiao, Sun-Lin, and Cheng [40] point out that the OMO learning mode is not only about a technology-rich or technology-enabled environment where knowledge and resources are passively accessed; rather, it provides an environment that is combined with technology, where the interaction between teachers and both offline and online students can be realized in a real-time basis. In other words, the OMO learning mode can provide open and flexible teaching and learning practices that allow students and teachers to interact in a more diverse way.

To provide an effective OMO learning experience that can cater to the new needs of students in the post-COVID-19 era, several Chinese universities developed and used the smart learning tool ClassIn $X$ as a pilot experiment. As Figure 1 shows, the typical OMO classroom design should have: (1) internet availability and access to connect the online and offline learning spaces, where the online students log in using their ClassIn $X$ accounts to virtually join the physical classroom and interact with the in-person students; (2) interactive boards where ClassIn $X$ is running, so that the teacher can use it to teach online and offline students at the same time; (3) sound equipment, including microphones to capture and transmit the sound of students and teachers within the classroom; (4) cameras to transmit the classroom interactions for the online students; and, (5) optional tablet computers that students can also use for different learning activities. It should be noted that full descriptions and depictions of the OMO classroom design are beyond the scope of this manuscript, as this study mainly focuses on the pilot experiment of using OMO learning.

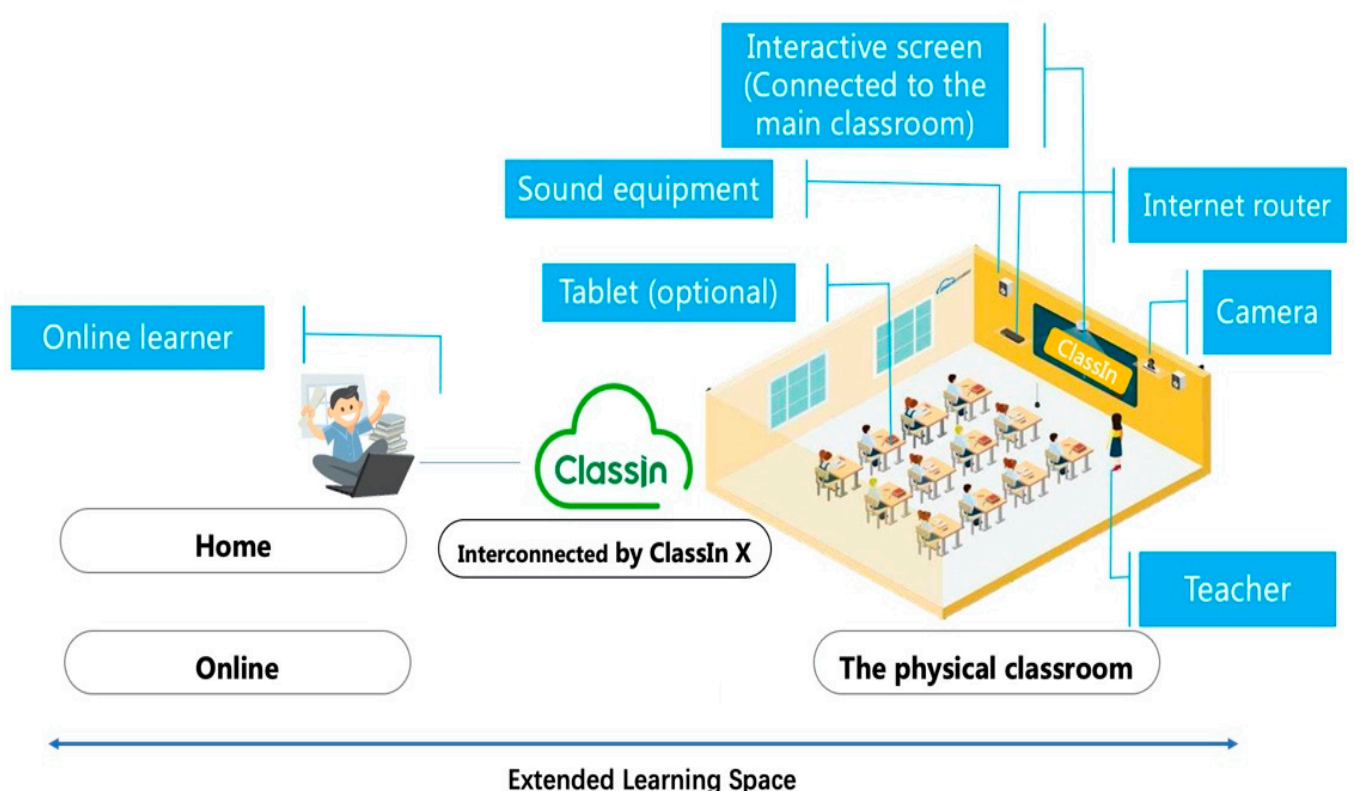

Figure 1. Typical OMO classroom design.

Figure 2 depicts a teacher using ClassIn $X$ to teach English. There is an interactive board with a smartpen for designing a learning activity in which students from the phys- 
ical classroom and students from the online classroom simultaneously work together to complete various English sentences (i.e., a fill-in-the-blank type of learning activity) under the guidance of the teacher. This functionality can foster learning interactions between the online and offline students at the same time, regardless of the learning space. Additionally, both online and offline students can see the learning interaction and receive oral feedback from their teacher as well as from their online and offline peers. ClassIn X provides a repository of open educational resources that the teacher can easily access and use as teaching materials. The teacher can also save the updated version of the teaching material (e.g., the teacher's notes) under an open license to the cloud, which can be reused by the students or by other teachers later on.

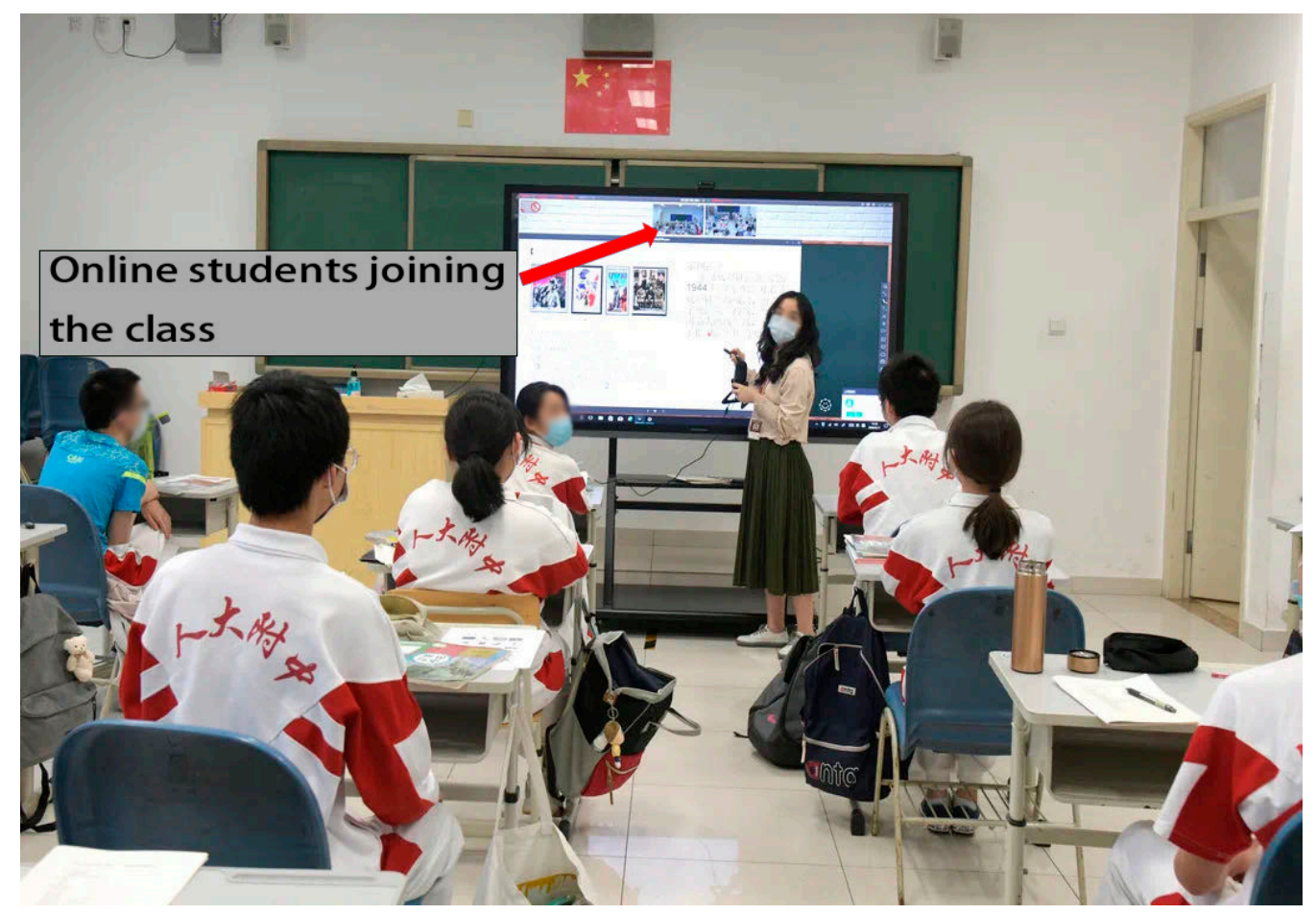

Figure 2. An example of an OMO learning scenario.

ClassIn $\mathrm{X}$ also provides virtual meeting rooms where the teacher can automatically or manually divide all the students (both online and offline) into groups and assign each group to a virtual room to work collaboratively on a specific learning task. For instance, as Figure 3 shows, the teacher assigned teams to virtual rooms to work together on English assignments. She then went through the virtual rooms one by one and displayed each group's work on the board, which all students can see, to discuss their answers.

As the learning space is now extended into both offline and online spaces, ClassIn $X$ provides several functionalities to facilitate learning management. For instance, the teacher can use the random selector functionality to select online students and assign them learning activities with the offline students. Additionally, the teacher can reward the students by giving oral encouragement or digital badges (see Figure 4). In this way, the teacher can provide instant encouragement and feedback for both the online and offline students. 


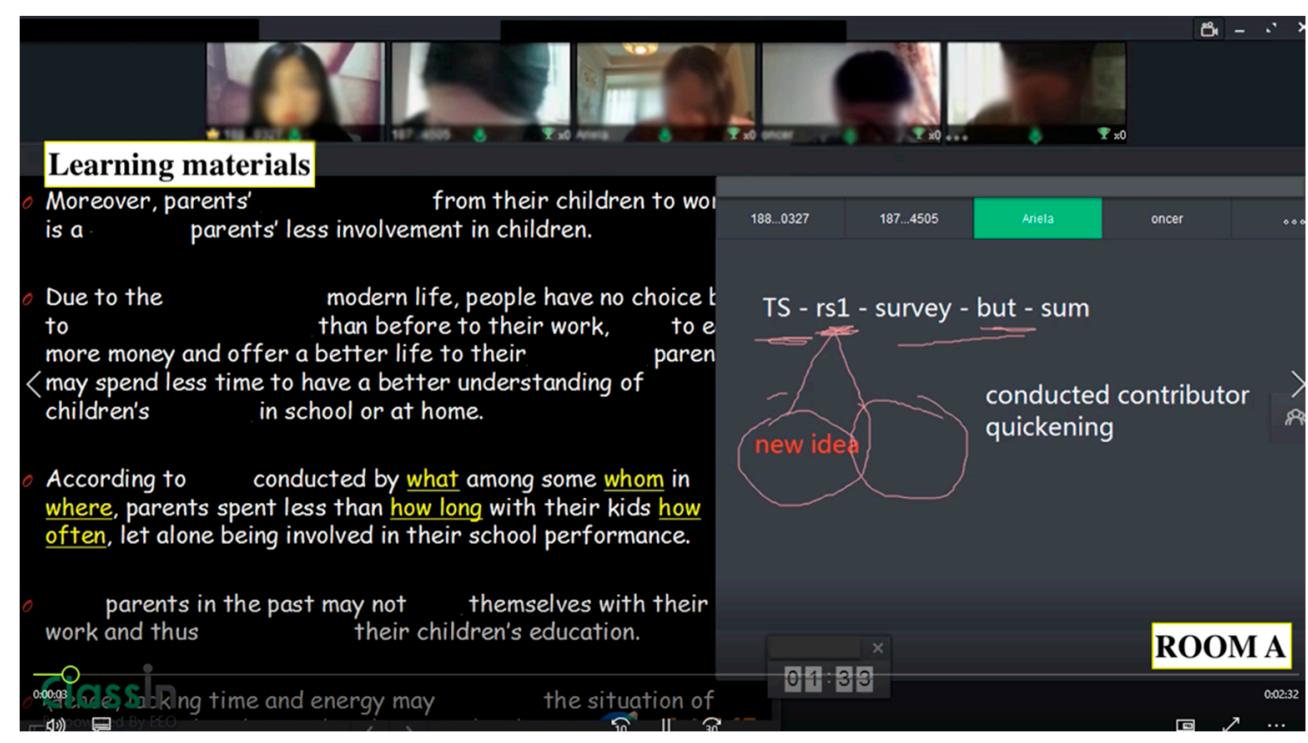

Figure 3. Teamwork activities during OMO learning.

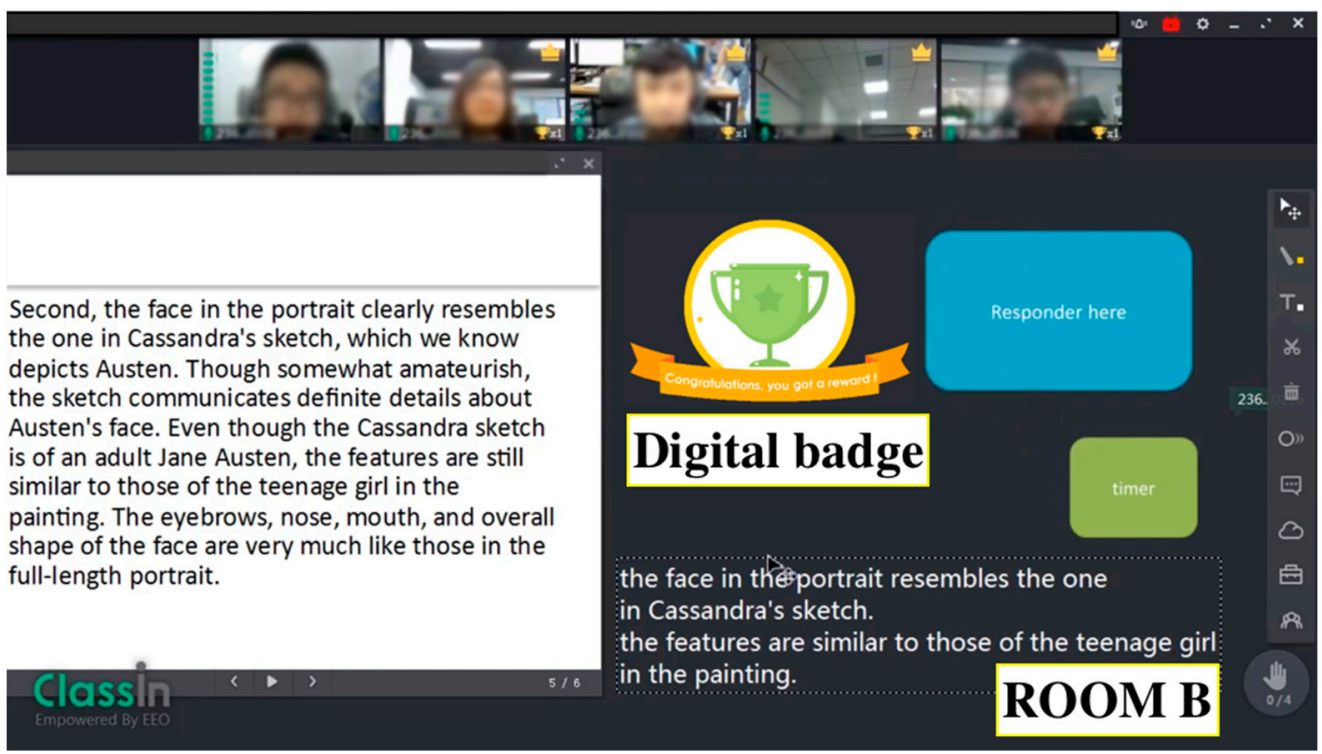

Figure 4. An example of awarded digital badges to students.

\section{Method}

\subsection{Theoretical Framework and Research Questions}

To evaluate innovative learning spaces, Radcliffe [41] proposed a Pedagogy-SpaceTechnology (PST) framework over a decade ago that is composed of three dimensions: (1) space, which focuses on how the learning space is designed to enable the learning and teaching processes; (2) technology, which focuses on the ways of using technologies in the newly developed learning space; and (3) pedagogy, which investigates the types of pedagogies and learning methods applied to support learning. The PST framework is designed for a range of users across a wide span of projects and institutions. For instance, $\mathrm{Ng}$ [42] used the PST framework to develop an online moot court in an Australian University that supported on-campus and off-campus students in practicing more efficiently. Pan and Zhu [43] used the PST framework to develop an e-learning space for the experimental teaching of economics in China.

This study discusses the innovative learning space of the OMO learning method. Hua et al. [44] highlight the importance of redesigning learning spaces based on the PST framework for better learning experiences and outcomes; this study thus uses this 
framework to investigate the efficiency and requirements for successful OMO learning. It should be noted that, to the best of our knowledge, no study has applied the PST framework for learning spaces in the COVID-19 context. Specifically, this study answers the following research questions, which are related to the three dimensions of the PST framework:

RQ1. How is the learning space designed to have a successful OMO teaching and learning experience?

RQ2. What are the functions of technology in the OMO teaching and learning experience?

RQ3. What are the perceptions of teachers and students towards pedagogy in the context of OMO teaching and learning?

\subsection{Participants and Procedure}

To address the research questions, we designed and implemented a qualitative twostage study using content analysis and a multiple-case study. After the three-month OMO learning process during the first semester of the 2020-2021 academic year in the postpandemic period, we conducted written interviews where the teachers and students had to answer each of the research questions via an online platform. We used interviews as a method because they allow participants to be more forthcoming in their answers [45]. As this pilot study reports, only a few public schools and universities adopted OMO learning in China in 2020; 10 teachers and 20 students voluntarily participated in this set of interviews. Specifically, the teachers used OMO for teaching the English language, while the students were undergraduates majoring in languages and enrolled in these English courses. The students voluntarily expressed their willingness to participate in the interviews and share their thoughts and experiences accordingly.

This study followed the British Educational Research Association's “Ethical Guidelines for Educational Research" [46], where the educators' institutions provided full ethical approval before data collection began. Participation in this research was voluntary, and the participants were free to withdraw at any stage. Each participant was fully informed of the purpose of the research in advance.

\subsection{Data Analysis}

As a first step, we used content analysis, one of the classical procedures for analyzing textual materials, to analyze the collected responses from the interviewees [47]. The analysis was based on the steps proposed by [48]. Specifically, three coders with experience in qualitative analysis and a minimum of five years of coding experience developed a coding scheme based on the three key research questions (see Table 1). The three coders first piloted the initial coding process. These coders then met several times to discuss and enhance the coding scheme through an analytic induction process, deleting, developing, or merging some codes together [49]. Additionally, to avoid "code drifting", the coders met regularly to discuss any misunderstandings or uncertain coding aspects as they emerged (e.g., peer debriefing) [50]. The coding results reached 75\% agreement at first. They then compared the results and reached a consensus through discussion, allowing for $100 \%$ agreement between all of the coders [50]. According to the coders, one of the challenges of this coding analysis was the quality of the provided data, as some responses were too vague and were excluded from the coding process after the coders reached a total agreement. Table 1 presents the final coding scheme they obtained. 
Table 1. Coding scheme.

\begin{tabular}{cl}
\hline \multicolumn{1}{c}{ Code } & \multicolumn{1}{c}{ When to Use } \\
\hline OMO Space Design and Requirements & $\begin{array}{l}\text { Use this code when the participants are talking } \\
\text { about the space design and skills to have a } \\
\text { successful OMO learning or teaching } \\
\text { experience. }\end{array}$ \\
Use this code when the participants are talking \\
about the different functionalities of \\
technologies in OMO learning.
\end{tabular}

As a second step, this study used a descriptive multiple-case study approach [51] with the intention to build an explanation of the teachers' OMO teaching experience (first case) and the students' OMO learning experience (second case). Descriptive case studies are useful in describing "an intervention or phenomenon and the real-life context in which it occurred" [52]. A multiple-case study approach can also provide a more robust and reliable study and can overcome weaknesses, including artificial conditions and uniqueness associated with single case studies [51,52].

\section{Results}

4.1. How Is the Learning Space Designed to Have a Successful OMO Teaching and Learning Experience?

To reflect the first research question, this pilot study focused on the space requirements of the OMO modality by collecting interview data with participants who have experienced OMO learning or teaching. Table 2 presents the results of the OMO requirements according to the analysis of students' and teachers' responses to the interviews. Table 2 presents the frequency of each code that appeared in the interviews. To better compare the two groups of participants (i.e., students and teachers), Table 2 presents the percentage of students and teachers mentioning each code-meaning the probability it is mentioned by a student or teacher. From these analyses of student and teacher responses, two main themes emerged relating to the infrastructure and skills needed to manage the new learning space. These two themes are discussed in the subsequent sections.

Table 2. Perceived skills, attitudes, and infrastructure required for OMO modality.

\begin{tabular}{ccc}
\hline Themes & $\begin{array}{c}\text { Percentage of the Students } \\
\text { Mentioning Each Code }\end{array}$ & $\begin{array}{c}\text { Percentage of the Teachers } \\
\text { Mentioning Each Code }\end{array}$ \\
\hline Infrastructure & $100 \%$ & $80 \%$ \\
ICT skill & $20 \%$ & $100 \%$ \\
Utilizing resources skill & $10 \%$ & $40 \%$ \\
Pedagogical skill & $0 \%$ & $100 \%$ \\
\hline
\end{tabular}

\subsubsection{Infrastructure}

Teachers and students mentioned several crucial elements for successful OMO teaching and learning experiences. Some of the items discussed included the classroom infrastructure-including interactive boards, ergonomic chairs and tables, the internet, and cameras. While describing their experiences in the OMO learning space, both teachers and students believed that these are fundamental for a successful OMO learning modality. Based on their responses, it is evident that the overall infrastructure is crucial to both teachers and students. Sufficient infrastructure support can facilitate communication for offline and online students at the same time, fostering collaborative learning tasks and discussion, and previewing and reviewing the learning materials. For instance, one of the students stated: 
"Offline facilities give people a sense of advancement. Freely movable chairs, large screens that can be directly projected on all sides, free-speaking classrooms, online teaching, multiple teachers, streamlined content, and different teaching methods, are features of an OMO class. It made me feel fresh and interested while learning a lot of knowledge."

One teacher highlighted the value of the big screen used in the context of OMO learning, saying:

"The equipment in OMO classroom is much more than traditional chalks and a blackboard. We use big screens in class with advanced technologies [to] teach in real-time both group[s] of students (online and offline)."

\subsubsection{Skills}

In terms of successful OMO learning, both students and teachers also mentioned that some skills are needed to manage this innovative space. As Table 2 shows, both students and teachers mentioned that multiple skills are required to have successful experiences in an OMO setting. The first skill that was frequently mentioned was the ICT skill, which indicates the capability of utilizing technological devices to conduct teaching and learning activities. For instance, students described some of the learning activities in which they had to use their technological devices:

"In the classroom, teachers share files through DingTalk, and we view those learning materials in real-time on our mobile phones. In addition, I like commenting on my classmates' post from my mobile phone. It keeps me updated."

Likewise, teachers found that ICT skills are necessary for them to manage the learning space. They described some of the activities that they had to do on a daily basis, including making PowerPoint slides and designing interactive quizzes or assignments. For example, one of the teachers mentioned:

"In the OMO teaching mode, teachers are required to use advanced teaching software to upload courseware and interact with it in real-time using hand gestures, hence we must be familiar with the tool and platform."

Furthermore, both teachers and students mentioned that "utilizing [digital] resources" is one of the indispensable skills in OMO teaching and learning, as it can help them choose the most appropriate Open Educational Resources (OER) to use. It can facilitate the generation of their learning reports as OER.

Finally, case comparison indicated that, on top of all these specific skills, teachers mentioned another skill that students did not mention-namely, pedagogical skills (see Table 1), including designing tasks and assignments and balancing work and interactions between online and offline students. Accordingly, several teachers mentioned that the OMO teaching experience had higher requirements, as they needed, for example, to design class activities that balanced online and offline interaction between students.

Specifically, when comparing student responses and teacher responses (see Table 2), we can conclude that solid infrastructure is one of the crucial elements in supporting OMO learning. Additionally, we see that students and teachers are expected to be equipped with certain skills in order to manage this learning space. Teacher acquisition of the skills needed to operate ICT and design pedagogical content is a major priority in this new learning space.

\subsection{What Are the Functions of Technology in the OMO Teaching and Learning Experience?}

In order to build a modality that facilitates learning and teaching, technologies that complement the space design should be taken into consideration as well. According to the data analyzed in this study (see Table 3), the perceived functions of technology in the OMO modality can be categorized as follows: (1) technology for ensuring health safety, (2) technology for supporting connectivity, (3) technology for offering flexibility, and (4) 
technology for facilitating communication. Table 3 shows the percentage of students and teachers mentioning each of the technology functionalities.

Table 3. Functionalities of technologies in the OMO modality.

\begin{tabular}{ccc}
\hline Functionality & $\begin{array}{c}\text { Percentage of the Students } \\
\text { Mentioning Each Code }\end{array}$ & $\begin{array}{c}\text { Percentage of the Teachers } \\
\text { Mentioning Each Code }\end{array}$ \\
\hline Ensuring Health Safety & $5 \%$ & $10 \%$ \\
Supporting Connectivity & $30 \%$ & $80 \%$ \\
Offering Openness and & $40 \%$ & $80 \%$ \\
Flexibility & $40 \%$ & $100 \%$ \\
Facilitating Communication & & \\
\hline
\end{tabular}

\subsubsection{Supporting Health and Safety}

Both teachers and students indicated that OMO learning is advantageous in terms of health safety, which is understood from the aspect of its advantage in reducing physical contact between students and teachers and maintaining social distancing during crises and emergencies. Students felt more comfortable with this modality, as one student elaborated:

"OMO modality is equipped with technologies that enable studying outside the physical classroom. I feel more secured and safer using OMO especially when there is a pandemic going on. I also don't have to worry that I might get left behind if I get sick and am not be able to go to school, since now I can join my classmates from home."

\subsubsection{Supporting Connectivity}

Connectivity is another commonly recognized function of OMO technologies. It refers to the expanded learning space, which allows extensive access to content knowledge and resources. Connectivity also relates to the possibility of applying different open educational practices for better learning outcomes. Such opportunities result from technologies embedded in the $\mathrm{OMO}$, which contains online educational resources, virtual meeting rooms, virtual discussion boards, and so on. One teacher explained how OMO demonstrates this function, by giving an example:

"To expand the influence of excellent teachers, the online-merge-offline model has been promoted, and many schools are also advancing OMO recently. Let an excellent teacher synchronize his or her courses to multiple classrooms. This modality hence expands the influence of high-quality courses and teachers as well as strengthens the network among schools."

\subsubsection{Offering Openness and Flexibility}

This study also found that openness and flexibility are two of the most recognized functions of OMO technologies, which were demonstrated in diverse forms. For instance, the students can revisit the recorded lectures online, under an open license, to learn again at their own pace. The students can also contribute to the teaching materials that are stored on the cloud. Flexibility and openness were also demonstrated by extending the learning spaces and the materials used for learning. As one of the students mentioned:

"I can have more practical activities, which are very innovative and interactive, as well as work in groups more freely."

\subsubsection{Facilitating Communication}

For both students and teachers, communication technologies are pivotal in teaching and learning. Some students stated that the efficiency of communication was improved in the OMO modality:

"It is not just simply listening to the teacher, but there are actual facilities and technologies available on-site, so that we can quickly respond to teachers and communicate with classmates offline and online." 
On the other hand, students and teachers also expressed that communication technology can be developed further since the current one was not as satisfying as they expected. For instance, some teachers mentioned that it was difficult to maintain communication between online and offline students at the same time. They recommended exploring the potential of online data to further facilitate the communication process. In addition, as they typically were not familiar with these technologies, they mentioned that they did not know how to position themselves in the classroom so that their face would be visible for both students in the classroom and students online, with their face toward the camera.

4.3. What Are the Perceptions of Teachers and Students towards Pedagogy in the Context of OMO Teaching and Learning?

Table 4 presents the percentage of students and teachers mentioning each of their perceptions towards OMO teaching and learning. The table shows that, compared with teachers, students demonstrated more positive perceptions after using the OMO modality, whereas teachers expressed their preferences less often.

Table 4. Teacher and student perceptions toward pedagogies in the OMO modality.

\begin{tabular}{ccc}
\hline Perception & $\begin{array}{c}\text { Percentage of the Students } \\
\text { Mentioning Each Code }\end{array}$ & $\begin{array}{c}\text { Percentage of the Teachers } \\
\text { Mentioning Each Code }\end{array}$ \\
\hline Positive & $100 \%$ & $20 \%$ \\
Reluctancy & $15 \%$ & $10 \%$ \\
Unfamiliarity & $40 \%$ & $20 \%$ \\
\hline
\end{tabular}

As Table 4 shows, teachers and students expressed positive perceptions regarding the confidence in operating $\mathrm{OMO}$ facilities, the fondness for certain pedagogical practices of the OMO approach, and the feeling of being interested or curious about the new modality. One student expressed her positive perceptions and noted her growth in knowledge:

"... (my learning efficiency and abilities are) improved, I think this learning mode is definitely more impressive and persuasive than memorizing theoretical knowledge, so it is improved through actual operation."

This study found two different negative perceptions in terms of questions about the extent to which teachers or students resist the adoption of pedagogies in the OMO modality. First, they expressed reluctancy, which means that the teacher or student was not willing to adopt the OMO learning or teaching experience because it was deemed to be more complicated, and it did not improve his/her teaching and learning experience or knowledge acquisition. Second, they may have expressed notions of unfamiliarity or confusion. Data under this category showed that teachers and students were confused by certain OMO procedures or were not familiar or comfortable with certain OMO features. However, they were still willing to employ this modality to gain more experience. Students expressed confusion as such:

"It was difficult sometimes to tell if the answer box in the picture is something that I can control. Also, the teacher is facing the camera. There is no sense of interaction sometimes."

\section{Discussion}

This pilot study discussed the emergence of the OMO learning mode to cater to the needs of students and teachers in the post-COVID-19 era in China. Specifically, this study discussed OMO learning from three perspectives: space design requirements, technology, and pedagogy. Based on the results, this study reveals that OMO learning has at least five key components or characteristics: (1) it is built on hybrid infrastructure with specific design requirements; (2) it provides an extended learning space regardless of students ${ }^{\prime}$ locations; (3) it enables open and flexible educational practices; (4) it needs suitable and interactive (open) resources; and (5) it requires a set of comprehensive competencies of 
teachers and students (see Figure 5). Each aspect is discussed below according to the obtained findings.

\section{Hybrid infrastructure}

5. Comprehensive Competency of Teachers and Students

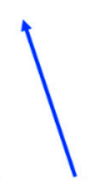

4. Suitable and Interactive (Open) Resources
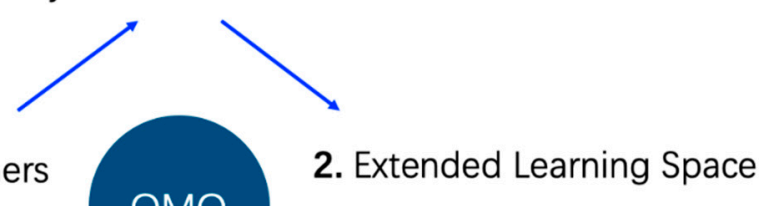

\section{$\mathrm{OMO}$}

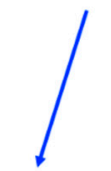

3. Open and Flexible

Educational Practices

Figure 5. OMO learning characteristics.

\subsection{Hybrid Infrastructure}

As shown in the obtained results, one of the core dimensions of OMO learning is a solid infrastructure that caters to hybrid teaching and learning scenarios based on open educational practices and resources. As such, reliable networks and digital devices are crucial in supporting online activities, such as video lecturing and discussions. At the same time, ergonomic classroom furniture is important for students who choose to attend class in person. With these factors in mind, Olapiriyakul and Scher [53] pointed out that infrastructure in a hybrid environment should support three aspects of learning and teaching: instruction, learning support, and communication. Based on our findings, all three functions of OMO infrastructure are confirmed by students and teachers.

However, our findings also showed that both students and teachers face several significant challenges with this hybrid infrastructure. For instance, challenges appear in fostering communication within a classroom to ensure better interactivity and learning experiences for online and offline students at the same time. Therefore, more research should be conducted regarding the components needed within an OMO infrastructure for a successful learning experience. For instance, stable cameras could be replaced by mobile cameras that track the teacher's movements within a classroom, which would promote a more efficient and authentic teaching process, even for those who are online.

\subsection{Extended Learning Spaces}

Our findings revealed that both teachers and students were enthusiastic about how OMO learning can extend the learning space to cover both online and offline environments. In particular, some students mentioned that this feature provided them with a feeling of safety by respecting social distancing. At the same time, OMO learning ensured that they could work effectively with all their peers, even though they were online. Therefore, OMO learning could be one of the solutions for maintaining education in times of uncertainty and crisis, as well as in difficult situations such as sickness, pregnancy, and adverse weather conditions.

Additionally, one of the features of OMO that needs to be utilized to its fullest is data collection and analysis. This function was mentioned by a few teachers, most of whom stressed that technology that does this would be of great use. In fact, real-time reports and dashboards could facilitate classroom management for teachers, especially in OMO learning where there are both online and offline students. In such situations, the teacher needs to keep an eye on both settings. Notably, an international project that focuses on learning analytics at Finland's Lahti University of Technology [54] has indicated that, since digital learning provides teachers with extensive data, teachers are expected to utilize that data to advance teaching. The project confirmed that technology-mediated interaction is 
efficient, that participative learning is fostered, and that data is collected and shown with visual clarity, which in turn gives teachers insights on teaching pedagogies. A scholar from Northeastern University [55] who has been using learning analytics in her online learning instruction also explained how learning analytics helped her understand students' learning behaviors in online classes during the pandemic. Therefore, more attention should be paid to integrating learning analytics (LA) and designing LA dashboards to facilitate the OMO teaching and learning processes.

\subsection{Open and Flexible Educational Practices}

As our results show, pedagogies in OMO learning are more open and flexible, as students can learn at their own pace by revisiting the recorded lectures and listening to the teacher's explanations. Additionally, OMO learning makes teaching practices more diverse, interactive, and open by using different technologies and platforms that allow for open collaboration. They also enhance the learning content and encourage students' sharing with their peers. More importantly, the learning process becomes more student-centered [30], as students can enrich the teaching materials with their peers and then save the resources, materials, and content on the cloud. In this context, Huang et al. [56] point out that open educational practices are an effective and innovative way to enable and maintain education from home during times of crisis and difficult situations.

As noted earlier, the OMO modality powerfully combines technology resources or augments learning with technology in order to enable rich interaction, collaboration, and communication between teachers and students on a real-time basis [31]. This augmented notion of the classroom dovetails with the idea that the OMO method includes open and flexible teaching and learning practices, meaning that students and teachers can interact in a more diverse way. As a result, students can learn without restrictions of time-for instance, by revisiting the recorded lectures under an open license.

Existing studies [57] have proven the flexibility of the online method. However, this study additionally proves that the OMO approach can maintain flexibility while catering to offline needs. In this context, Huang et al. [57] highlight the importance of flexible and open learning in times of crisis, as this can reduce the pressure on students when it comes to health and pedagogical concerns. It is widely recognized that flexible learning is a key feature in educational strategies at both the individual and institutional levels [58]. We suggest that the flexibility of education should be considered as a normal practice for education administrators, policymakers, instructional designers, and instructors across educational sectors and disciplines, while not decreasing the success criteria or the performance indicators. Self-paced and/or flexible learning should demand the same quality of education as that of other modalities. According to this pilot study, OMO is one of the feasible modalities to leverage this flexible concept and transform it from an instructional ideal or optimistic suggestion to a viable reality that can be operationalized to help society address and potentially overcome a once-in-a-century global pandemic.

\subsection{Suitable and Interactive (Open) Resources}

As our results show, it is vital for both students and teachers to be able to retrieve and reutilize digital and online (open) resources provided in the OMO modality. OMO learning requires educators to make sure that they are equipped with suitable and interactive resources, which can be indispensable in supporting online and offline interactions. For instance, students can use a physical textbook while they finish exercises shown on an interactive board. In another case, the learning material is provided in both paper and digital formats, with some slight differences, which can be used to prompt students to collaborate with their classmates from afar to complete the tasks. Therefore, teachers should develop their skills in terms of selecting, using, evaluating, and reusing digital (open) educational resources to support OMO learning, with special stress on resource editing and authoring, which allows for a healthy resource exchange within the community. This could be achieved by providing specific training-for instance, on how to remix a 
specific resource and what type of open license should be selected. Indeed, a study about the application of OEP and OER to maintain education during the COVID-19 pandemic revealed that more training on how to be effective facilitators of the learning process should be provided to teachers [59].

\subsection{Comprehensive Competency of Teachers and Students}

This pilot study has suggested that OMO learning requires instructors to develop different digital teaching competencies, including operating online platforms, communicating with online and offline participants, and utilizing resources. OMO learning would bring about a whole set of comprehensive competencies for both teachers and students. For teachers, their ability to manage physical and virtual classes simultaneously will be strengthened. For students, such competencies highlight their ability to adapt to tangible and intangible environments, to focus on information attained-whether online or offline, and to collaborate with their physical and virtual peers at the same time.

In order to build the competencies of students and teachers, studies have shown that training is essential in terms of introducing new modalities. Goodyear et al. [60] point out that useful and effective training should establish ground rules of online education, create a community, manage communications, and identify competencies of different roles. In a circumstance where a global pandemic is interrupting learning, such training is more easily adopted and deemed vital by all stakeholders. A study of teacher education in Germany demonstrated that ICT skill is extremely vital and instrumental in adapting to online teaching in the context of the pandemic [61]. Similarly, the European Commission's science and knowledge service recently released the Digital Competence Framework for Educators (DigCompEdu) [62], which aims to detail how digital technologies can be used to enhance and innovate education and training. DigCompEdu covers 22 competencies organized into six areas, and the focus is not on technical skills. In order to further adopt the OMO modality in teaching and learning, training that focuses on digital teaching competencies is highly needed. Furthermore, methodology in online, blended, and hybrid settings is the backbone for successful implementation. Functional and specific competencies that address this methodology are also necessary for satisfactory implementation of OMO learning.

\section{Conclusions}

To summarize, this paper exemplifies the future of sustainable education by presenting a pilot study utilizing OMO learning in the post-COVID-19 era in China. While this mode of learning can extend the learning space, ensure health and safety during a pandemic, and provide flexible and open learning methods and interactions, further investigation is clearly needed to identify the most suitable infrastructure components (e.g., cameras, smart devices and boards, microphones, etc.) to enhance the instructional experience of both teachers and students. Additionally, since OMO learning is unlike either traditional classroom instruction or fully online learning, specific training procedures are needed to advance the competencies of teachers and students in OMO learning. The OMO approach is addressing a long-term, sustainable implementation to ensure effective education, learner performance, and teacher engagement. OMO allows for combined settings to be integrated, in order to adapt to current and potential future scenarios that challenge traditional educational models.

It should be noted that this paper has several limitations. For instance, this study relies mainly on qualitative analysis with a limited sample size. Therefore, the obtained results cannot be generalized and more quantitative analyses with larger sample sizes should be conducted in the future to draw in-depth conclusions about the teaching and learning experiences in the OMO method. Future research could focus on investigating the impact of OMO learning on learning performance and motivation in order to draw conclusions about how this mode of learning could affect the learning process and educational outcomes. 
Author Contributions: Conceptualization, Y.S. and C.J.B.; Data curation, H.W.; Formal analysis, H.W.; Investigation, D.B.; Methodology, R.H. and J.Y.; Validation, A.T., Y.S., and C.J.B.; Visualization, J.Y.; Writing-original draft, R.H. and A.T.; Writing—review and editing, D.B. Each author contributed evenly to this paper. All authors have read and agreed to the published version of the manuscript.

Funding: There was no funding that supported this study.

Institutional Review Board Statement: The study was conducted according to the guidelines of the Declaration of Helsinki, and approved by the Institutional Review Board (or Ethics Committee) of Universidad Internacional de La Rioja (UNIR) (date of approval: 5 June 2020).

Informed Consent Statement: Informed consent was obtained from all subjects involved in the study.

Data Availability Statement: The datasets used during the current study are available from the corresponding author on reasonable request.

Acknowledgments: The authors would like to thank the ClassIn team, specifically Zhicheng (Daniel) Ji and Chunchun (Phyllis) Zhang for their incredible assistance in conducting this study.

Conflicts of Interest: The authors declare no conflict of interest.

\section{References}

1. UNICEF. Keeping the World's Children Learning through COVID-19. Available online: https:/ /www.unicef.org/coronavirus / keeping-worlds-children-learning-through-covid-19 (accessed on 20 April 2020).

2. UNESCO. UNESCO Launches Global Consultation on the Futures of Education Initiative. Available online: https://en.unesco. org/futuresofeducation/initiative (accessed on 12 January 2021).

3. UNICEF. Coronavirus Disease (COVID-19) Information Centre. Available online: https://www.unicef.org/coronavirus / covid-19 (accessed on 20 January 2021).

4. Kanwar, A.; Daniel, J. Report to Commonwealth Education Ministers: From Response to Resilience. Available online: http: / / oasis.col.org/handle/11599/3592 (accessed on 23 June 2020).

5. Reliefweb. Hundreds of Millions of Students Now Learning from Home after Coronavirus Crisis Shuts Their Schools. Available online: https: / / reliefweb.int/report/world/hundreds-millions-students-now-learning-home-after-coronavirus-crisis-shutstheir (accessed on 13 January 2021).

6. Bergdahl, N.; Nouri, J. Covid-19 and Crisis-Prompted Distance Education in Sweden. Technol. Knowl. Learn. 2020, 1-17. [CrossRef]

7. Hodges, C. The Difference between Emergency Remote Teaching and Online Learning. Available online: https://er.educause. edu/articles / 2020/3/the-difference-between-emergency-remote-teaching-and-online-learning (accessed on 6 February 2021).

8. Van der Spoel, I.; Noroozi, O.; Schuurink, E.; van Ginkel, S. Teachers' online teaching expectations and experiences during the Covid19-pandemic in the Netherlands. Eur. J. Teach. Educ. 2020, 43, 623-638. [CrossRef]

9. La Velle, L.; Newman, S.; Montgomery, C.; Hyatt, D. Initial teacher education in England and the Covid-19 pandemic: Challenges and opportunities. J. Educ. Teach. 2020, 46, 596-608. [CrossRef]

10. Artacho, E.G.; Martínez, T.S.; Martín, J.L.O.; Marín, J.A.M.; García, G.G. Teacher Training in Lifelong Learning-The Importance of Digital Competence in the Encouragement of Teaching Innovation. Sustain. J. Rec. 2020, 12, 2852. [CrossRef]

11. Moreno-Guerrero, A.J.; Miaja-Chippirraz, N.; Bueno-Pedrero, A.; Borrego-Otero, L. The Information and Information Literacy Area of the Digital Teaching Competence. Rev. Electrón. Educ. 2020, 24, 521-536.

12. Tømte, C.; Enochsson, A.B.; Buskqvist, U.; Kårstein, A. Educating Online Student Teachers to Master Professional Digital Competence: The TPACK-framework Goes Online. Comput. Educ. 2015, 84, 26-35. [CrossRef]

13. The Washington Post, Reopened Schools in Europe and Asia Have Largely Avoided Coronavirus Outbreaks. They Have Lessons for the U.S. Available online: https:/ / www.washingtonpost.com/world/europe/schools-reopening-coronavirus/2020/07/10/8 65fb3e6-c122-11ea-8908-68a2b9eae9e0_story.html (accessed on 11 July 2020).

14. Civil Aviation Administration of China, Preventing Spread of Coronavirus Disease 2019 (COVID-19) Guideline for Airlines. Available online: http:/ / www.caac.gov.cn/en/XWZX/202006/W020200626738640795089.pdf (accessed on 21 January 2021).

15. Centers for Disease Control and Prevention, COVID-19 Travel Recommendations by Destination. Available online: https: / / www.cdc.gov / coronavirus/2019-ncov/travelers/map-and-travel-notices.html (accessed on 19 February 2021).

16. Xiao, C.; Li, Y. Analysis on the Influence of the Epidemic on the Education in China. In Proceedings of the 2020 International Conference on Big Data and Informatization Education (ICBDIE), Shenzhen, China, 4-6 December 2020.

17. The East Africa, Kenya Schools to Reopen in January. Available online: https://www.theeastafrican.co.ke/tea/news/east-africa/ kenyan-schools-to-reopen-in-january-3023514 (accessed on 17 December 2020).

18. Indian Express, How and When Will Schools Reopen. Available online: https://indianexpress.com/article/explained/how-andwhen-will-schools-reopen-what-will-change-for-students-6704619/ (accessed on 15 February 2021).

19. Guthrie, B.L.; Tordoff, D.M.; Meisner, J.; Tolentino, L.; Jiang, W.; Fuller, S.; Green, D.; Louden, D.; Ross, J.M. Summary of School Re-Opening Models and Implementation Approaches during the COVID 19 Pandemic. Available online: https: / / www.doh.wa.gov/Portals/1/Documents/1600/coronavirus/20200706-SchoolsSummary.pdf (accessed on 22 January 2021). 
20. The University of Edinburgh, Information about Semester 2. Available online: https://www.ed.ac.uk/news/covid-19/currentstudents/semester-2 (accessed on 17 February 2021).

21. Fordham University. Class Held Fully Online. Available online: https://www.fordham.edu/info/21360/academic_records_ registrar/11825/courses_held_fully_online (accessed on 10 January 2021).

22. New York University. A Look Ahead to Spring 2021 and Important Proposed Changes to the Academic Calendar. Available online: https:/ / www.nyu.edu/about/leadership-university-administration/office-of-the-president/communications/a-lookahead-to-spring2021-and-important-proposed-changes-to-the-academic-calendar.html (accessed on 20 October 2020).

23. Orellana, A. Class size and interaction in online courses. In The Perfect Online Course: Best Practices for Designing and Teaching, North Carolina; IAP: Charlotte, NC, USA, 2009; pp. 117-135.

24. Caulkins, J.; Grass, D.; Feichtinger, G.; Hartl, R.; Kort, P.M.; Prskawetz, A.; Seidl, A.; Wrzaczek, S. How long should the COVID-19 lockdown continue? PLoS ONE 2020, 15, e0243413. [CrossRef] [PubMed]

25. Petraglia, J. The real world on a short leash: The (mis) application of constructivism to the design of educational technology. Educ. Technol. Res. Dev. 1998, 46, 53-65. [CrossRef]

26. Herrington, J.; Reeves, T.C.; Oliver, R. A Guide to Authentic e-Learning; Routledge: New York, NY, USA, 2010.

27. Ertmer, P.; Ottenbreit-Leftwich, A.T. Teacher Technology Change: How Knowledge, Confidence, Beliefs and Culture Intersect. J. Res. Technol. Educ. 2010, 42, 255-284. [CrossRef]

28. Romeo, G.; Lloyd, M.; Downes, T. Teaching Teachers for the Future (TTF): Building the ICT in education capacity of the next generation of teachers in Australia. Australas. J. Educ. Technol. 2012, 28, 949-964. [CrossRef]

29. Wiley, D.; Hilton, J.L., III. Defining OER-Enabled Pedagogy. Int. Rev. Res. Open Distrib. Learn. 2018, 19. [CrossRef]

30. Mintz, S. Making Online Learning Active. Available online: https://www.insidehighered.com/blogs/higher-ed-gamma/ making-online-learning-active (accessed on 6 July 2020).

31. Toor, R. Turns Out You Can Build Community in a Zoom Classroom, The Chronicle of Higher Education. Available online: https:/ / www.chronicle.com/article/Turns-Out-You-Can-Build/249038 (accessed on 23 June 2020).

32. Veletsianos, G. The 7 Elements of a Good Online Course, The Conversation. Available online: https://theconversation.com/the7-elements-of-a-good-online-course-139736 (accessed on 21 January 2021).

33. Filho, W.L.; Price, E.; Wall, T.; Shiel, C.; Azeiteiro, U.M.; Mifsud, M.; Brandli, L.; Farinha, C.S.; Caeiro, S.; Salvia, A.L.; et al. COVID-19: The impact of a global crisis on sustainable development teaching. Environ. Dev. Sustain. 2021, 1-22.

34. Wolff, L.-A. Sustainability Education in Risks and Crises: Lessons from Covid-19. Sustain. J. Rec. 2020, 12, 5205. [CrossRef]

35. McCowan, T. Universities and the post-2015 development agenda: An analytical framework. High. Educ. 2016, 72, 505-523. [CrossRef]

36. Karatzoglou, B. An in-depth literature review of the evolving roles and contributions of universities to education for sus-tainable development. J. Clean. Prod. 2013, 49, 44-53. [CrossRef]

37. Tsai, T.-M.; Wang, W.-N.; Lin, Y.-T.; Choub, S.-C. An O2O Commerce Service Framework and its Effectiveness Analysis with Application to Proximity Commerce. Procedia Manuf. 2015, 3, 3498-3505. [CrossRef]

38. Hilliard, J.; Kear, K.; Donelan, H.; Heaney, C. Students' experiences of anxiety in an assessed, online, collaborative project. Comput. Educ. 2020, 143, 103675. [CrossRef]

39. Wang, C.; Fang, T.; Gu, Y. Learning performance and behavioral patterns of online collaborative learning: Impact of cog-nitive load and affordances of different multimedia. Comput. Educ. 2020, 143, 103683. [CrossRef]

40. Xiao, J.; Sun-Lin, H.-Z.; Cheng, H.-C. A framework of online-merge-offline (OMO) classroom for open education. Asian Assoc. Open Univ. J. 2019, 14, 134-146. [CrossRef]

41. Radcliffe, D. A Pedagogy-Space-Technology (PST) Framework for Designing and Evaluating Learning Places. In Proceedings of the Next Generation Learning Spaces 2008 Colloquium; University of Queensland: Brisbane, Australia, 2009; pp. 11-16.

42. $\mathrm{Ng}$, J. Innovating with Pedagogy-Space-Technology (PST) Framework: The Online Moot Court. Learn. Communities Int. J. Learn. Soc. Context. 2015, 18, 52-65. [CrossRef]

43. Pan, X.; Zhu, L. An E-learning Space for the Economics Experimental Teaching Based on Pedagogy-Space-Technology Framework. In Proceedings of the 2020 International Conference on Advanced Education, Management and Information Technology (AEMIT 2020), Shanghai, China, 22-23 March 2020.

44. Hua, Z.; Ma, Z.; Ding, Y. A research and case study of purpose oriented PST framework for redesigning learning spaces. China Educ. Technol. 2017, 361, 76-81.

45. Tlili, A.; Essalmi, F.; Jemni, M. Improving learning computer architecture through an educational mobile game. Smart Learn. Environ. 2016, 3. [CrossRef]

46. British Educational Research Association. Available online: https://www.bera.ac.uk/researchers-resources/publications/ethicalguidelines-for-educational-research-2011 (accessed on 31 July 2011).

47. Flick, U. An Introduction to Qualitative Research, 4th ed.; Sage: London, UK, 2009.

48. Erlingsson, C.; Brysiewicz, P. A hands-on guide to doing content analysis. J. Emerg. Med. 2017, 7, 93-99. [CrossRef]

49. Richardson, J.C.; Koehler, A.A.; Besser, E.D.; Caskurlu, S.; Lim, J.; Mueller, C.M. Conceptualizing and investigating instructor presence in online learning environments. Int. Rev. Res. Open Distrib. Learn. 2015, 16. [CrossRef]

50. Creswell, J.W. Research Design: Qualitative, Quantitative, and Mixed Methods Approaches, 4th ed.; Sage: Thousand Oaks, CA, USA, 2014; pp. 203-204. 
51. Yin, R.K. Case Study Research: Design and Methods, 4th ed.; Sage: Riverside, CA, USA, 2009.

52. Baxter, P.; Jack, S. Qualitative case study methodology: Study design and implementation for novice researchers. Qual. Rep. 2008, 13, 544-559.

53. Olapiriyakul, K.; Scher, J.M. A guide to establishing hybrid learning courses: Employing information technology to create a new learning experience, and a case study. Internet High. Educ. 2006, 9, 287-301. [CrossRef]

54. Lahti University. International CEPHEI Project Aims to Build an e-Learning Platform that Follows Progress and Tests Knowledge. Available online: https:/ / www.lut.fi/web/en/news/-/asset_publisher/1Gh4SAywhcPu/content/international-cephei-projectaims-to-build-an-e-learning-platform-that-follows-progress-and-tests-knowledge (accessed on 24 August 2018).

55. James, N. Re: Learning Analytics as an Important Service in This New COVID and Mandatory e-Learning Situation. Available online: https:/ / www.researchgate.net/post/Learning-Analytics-as-an-important-service-in-this-new-COVID-and-mandatorye-learning-situation/5f7b01303e3e205531216d71/citation/download (accessed on 10 January 2021).

56. Huang, R.; Liu, D.; Tlili, A.; Knyazeva, S.; Chang, T.W.; Zhang, X.; Burgos, D.; Jemni, M.; Zhang, M.; Zhuang, R.; et al. Guidance on Open Educational Practices during School Closures: Utilizing OER under COVID-19 Pandemic in Line with UNESCO OER Recommendation; Smart Learning Institute of Beijing Normal University: Beijing, China, 2020. Available online: https://educacion.udd.cl/ aprendizaje180/ files/2020/12/UNESCO-IITE-Guidance-on-Open-Educational-Practices-during-School-Closures-2020.pdf (accessed on 24 January 2021).

57. Huang, R.; Tlili, A.; Yang, J.; Chang, T. Handbook on Facilitating Flexible Learning during Educational Disruption: The Chinese Experience in Maintaining Undisrupted Learning in COVID-19 Outbreak; Smart Learning Institute of Beijing Normal University: Beijing, China, 2020. Available online: https:/ /iite.unesco.org/wp-content/uploads/2020/03/Handbook-on-Facilitating-Flexible-Learningin-COVID-19-Outbreak-SLIBNU-V1.2-20200315.pdf (accessed on 20 January 2021).

58. Ryan, A.; Tilbury, D. Flexible Pedagogies: New Pedagogical Ideas, Higher Education Academy, November 2013. Available online: https://www.heacademy.ac.uk/sites/default/files/resources/npi_report.pdf (accessed on 13 January 2021).

59. Zhang, X.; Tlili, A.; Huang, R.; Chang, T.; Burgos, D.; Yang, J.; Zhang, J. A Case Study of Applying Open Educational Practices in Higher Education during COVID-19: Impacts on Learning Motivation and Perceptions. Sustain. J. Rec. 2020, 12, 9129. [CrossRef]

60. Goodyear, P.; Salmon, G.; Spector, J.M.; Steeples, C.; Tickner, S. Competences for online teaching: A special report. Educ. Technol. Res. Dev. 2001, 49, 65-72. [CrossRef]

61. König, J.; Jäger-Biela, D.J.; Glutsch, N. Adapting to online teaching during COVID-19 school closure: Teacher education and teacher competence effects among early career teachers in Germany. Eur. J. Teach. Educ. 2020, 43, 608-622. [CrossRef]

62. The European Commission's Science and Knowledge Service. Available online: https://ec.europa.eu/jrc/en/digcompedu (accessed on 11 November 2020). 